\title{
Bioinspired Microsphere-Embedded Adhesive Architectures for Electrothermally Actuating Transport Device of Dry/Wet Pliable Surfaces
}

\author{
Sangyul Baik ${ }^{1},{ }^{\dagger} *$ Gui Won Hwang ${ }^{1}{ }^{\dagger}$ Siyeon Jang ${ }^{2}$, Suyeon Jeong ${ }^{2}$, Ki Hyun Kim ${ }^{3}$, Tae-Heon \\ Yang ${ }^{4}$, Changhyun Pang ${ }^{1, *}$
}

${ }^{1}$ School of Chemical Engineering, Sungkyunkwan University (SKKU), Suwon, Gyeonggi-do 16419, Republic of Korea.

${ }^{2} S K K U$ Advanced Institute of Nanotechnology (SAINT), Sungkyunkwan University, Suwon, Gyeonggi-do 16419, Republic of Korea.

${ }^{3}$ School of Pharmacy, Sungkyunkwan University, Sungkyunkwan University, Suwon, Gyeonggi-do 16419, Republic of Korea.

${ }^{4}$ Department of Electronic Engineering, Korea National University of Transportation, Chungju, Republic of Korea.

[†] S. B. and G. W. H. contributed equally to this work.

\author{
*Corresponding author: \\ Dr. Sangyul Baik \\ School of Chemical Engineering \\ Sungkyunkwan University, \\ 2066 Seobu-ro, Jagnan-gu, Suwon, Gyeonggi-do 440-746, South Korea. \\ Email: bsy7863@gmail.com \\ Prof. Changhyun Pang \\ School of Chemical Engineering \\ Sungkyunkwan University, \\ 2066 Seobu-ro, Jagnan-gu, Suwon, Gyeonggi-do 440-746, South Korea. \\ Email: chpang@skku.edu
}

KEYWORDS: Dry adhesive, Biomimetics, Microstructures, Flexible devices, Polymer actuators 


\section{Supporting Methods Section}

\section{Fabrication of PDMS-based hole patterns:}

We prepared the silicon molds with hole patterns (radii of $150 \mathrm{~mm}$; width-to-depth ratio of 1) via photolithography and subsequent reactive ion etching. The molds were treated with a fluorinated self-assembled monolayer (SAM) solution ((tridecafluoro-1,1,2,2tetrahydrooctyl)-trichlorosilane (FOTCS); Gelest Corporation, Morrisville, USA) diluted to $0.03 \mathrm{M}$ in anhydrous heptane (Samchun Chemical, Pyeongtaek-si, Gyeonggi-do, South Korea) in an argon atmosphere. Drops of polydimethylsiloxane (PDMS, Sylgard 184 silicone elastomer kit, Dow Corning) prepolymer were dispensed onto the silicon molds and cured at $80{ }^{\circ} \mathrm{C}$ for $2 \mathrm{~h}$ to replicate the pillar PDMS molds. The PDMS molds were treated with a fluorinated SAM solution (FOTCS) and PDMS prepolymer was casted on the SAM-treated PDMS mold and cured at $70{ }^{\circ} \mathrm{C}$ for $2 \mathrm{~h}$ for the purpose of fabricating the hole-patterned PDMS patch.

\section{Preparation of microparticles by emulsion polymerization:}

Polydimethylsiloxane (PDMS, Sylgard 184 silicone elastomer kit, Dow Corning) is used for making microparticles. PDMS precursors for microparticles consists of siloxane oligomers, part A, and curing agents, part B. Total $3.3 \mathrm{~g}$ of precursors are thoroughly mixed using a vortex mixer, the mixed weight ratio corresponds to part $\mathrm{A}$ : part $\mathrm{B}=10: 1$ in a dispersed phase $^{1}$. Subsequently, a solution is prepared by dissolving $1 \mathrm{wt} \%$ of polyvinyl alcohol (PVA, Sigma-Aldrich) molecules that act as surfactants in deionized (DI) water. Forming stable droplets through emulsification significantly depends on the use of surfactants. PVAs are the surfactants can stabilize the oil-water fluid interfaces of the droplets ${ }^{2}$. PVAs are fully dissolved in DI water by stirring for 6 hours at $90{ }^{\circ} \mathrm{C}$. The $3.3 \mathrm{~g}$ of PDMS mixtures are emulsified in 40 $\mathrm{ml}$ of the PVA solution by using a homogenizer equipment for 5 minutes and then stable PDMS 
droplets are generated in the emulsion. PDMS microparticles are solidified subsequent to curing thermally for 2 hours at $70{ }^{\circ} \mathrm{C}$. Finally, the $240-260 \mu \mathrm{m}$ pore size of a mesh is utilized so that the desired size $(250 \mu \mathrm{m})$ of PDMS particles are obtained.

\section{Dip-coating for sealing the PEDOT:PSS/PDMS bilayer:}

To prevent the delamination between PEDOT:PSS and PDMS layers, we encapsulated the PEDOT:PSS layer within the OMS patch, wherein the PEDOT:PSS layer was sealed with the upper $(\sim 52 \mu \mathrm{m})$ and lower $(\sim 1 \mathrm{~mm})$ PDMS layers, using a dip-coating technique. As a protective layer on the OMS-patterned surface, drops of the polyurethane(acrylate) (PUA) prepolymer (PUA KSM R301; MCNet Co., Ltd, South Korea) were dispensed onto the OMSpatterned surface, and a polyethylene terephthalate (PET) film (thickness: $50 \mu \mathrm{m}$ ) was pressed slightly against the liquid drops to act as a supporting backplane. After curing process of the protective layer by ultraviolet (UV) exposure for 3 hours, a dip-coating solution was prepared by dissolving 3.3g PDMS precursor with $10 \mathrm{wt} \%$ curing agents in $10 \mathrm{ml}$ hexane by using vortex for $30 \mathrm{~min}$. After the PDMS precursor was entire dissolved in hexane, as-prepared OMS patch with PUA layer (protective layer) was dipped into the solution for $10 \mathrm{sec}$, dried for $3 \mathrm{~min}$ under the atmosphere condition, and then cured for 2 hours at $80{ }^{\circ} \mathrm{C}$. The dip-coating process repeated two or three times, and the protective layer was removed by peeling it.

\section{Adhesion test:}

Normal adhesion tests against Si wafer (Figure S-3) - FSR, PCB, and ITO film (Figure S-9) in dry ( $\sim 50 \%$ relative humidity), underwater, and underoil conditions (fully submerged conditions) were all performed using a custom-build equipment (Adhesion tester, Neo-Plus, Korea). The adhesive patch affixed to jig was prepared, and it was well-aligned to substrates as shown in the Figure S-3b. Preload $\left(1.0-3.5 \mathrm{~N} / \mathrm{cm}^{2}\right)$ then applied onto the adhesive sample 
for $\sim 5$ secs and detached for measurement. All of the adhesion tests were repeated with in-situ experiments at least 10 times on the substrates at ambient temperature, and the average values were plotted.

\section{Suction effect analysis:}

Using confocal laser scanning microscope (Leica TCS SP8. Inc, USA), we measured the position of water mixed with a fluorescent material (Fluorescein isothiocyanate, emission at $519 \mathrm{~nm}$ and excitation at $495 \mathrm{~nm}$ ) to monitor the stepwise behaviors of OMSs. Stage I is measured in the state of the OMS located on the water-covered substrate (Figure 5a (i)). After applying preload to the OMS adhesives, Stage III is measured in the state of the preload removed from the patch and the capturing water in the upper chambers $\left(\mathrm{C}_{1}\right)$ (Figure 5a (iii)).

\section{Practical demonstrations of the polymeric bilayer actuator:}

The polymeric bilayer actuator is first affixed to a customized, 3D printed design, which is then connected to a commercial robotic manipulator (OpenMANIPULATOR-X RMX52-TNM, ROBOTIS). Various brittle objects (PCB, FSR, ITO film) are placed onto numbered boards, and we conducted pick and place various dry and wet target at different location by controlling a robotic arm and electric input. 
Supporting Table 1. Comparison of various bioinspired adhesive architectures with or without switchable adhesion property

\begin{tabular}{|c|c|c|c|c|c|c|}
\hline & Architecture & Materials & $\begin{array}{l}\text { Adhesion strength } \\
\text { in dry condition }\end{array}$ & $\begin{array}{l}\text { Adhesion strength } \\
\text { in wet condition }\end{array}$ & Active Actuation & \\
\hline \multirow{10}{*}{$\begin{array}{c}\text { Geko } \\
\text { inspired } \\
\text { pillar } \\
\text { structure }\end{array}$} & Micropillar & PDMS & $1.3 \mathrm{~N} / \mathrm{cm}^{2}$ (Pig skin) & $\mathrm{x}$ & $\mathrm{x}$ & [14] \\
\hline & Nanohair & PUA & $26 \mathrm{~N} / \mathrm{cm}^{2}$ (Si wafer) & $\mathrm{x}$ & $\mathrm{x}$ & [16] \\
\hline & Geko & PDMS & $13 \mathrm{~N}$ (Glass) & $\mathrm{x}$ & $\mathrm{x}$ & [26] \\
\hline & Geko & Loctite & $18.4 \pm 3.5 \mathrm{nN} / \#$ (N-phil) & $3.3 \pm 0.3 \mathrm{nN} / \#(\mathrm{~N}-\mathrm{phil})$ & $x$ & [38] \\
\hline & Geko & ST-1060 & $0.23 \mathrm{~N} / \mathrm{cm}^{2}$ (Glass) & $\mathrm{x}$ & $\begin{array}{c}0 \\
\text { Pneumatic }\end{array}$ & [22] \\
\hline & Microtip & $\begin{array}{l}\text { Shape Memory polymer } \\
\text { Epon } 826, \text { Jeffamine D230 }\end{array}$ & $184 \mathrm{~N} / \mathrm{cm}^{2}$ (Glass) & $\mathrm{x}$ & $\begin{array}{c}\mathrm{O} \\
\text { Temperature }\end{array}$ & [32] \\
\hline & Geko & BIPMTD & $0.73 \pm 0.23 \mathrm{mN}$ (glass) & $\mathrm{x}$ & $\begin{array}{c}0 \\
\text { Light }\end{array}$ & [30] \\
\hline & Geko & Liquid crystalline elastomer & $1.1 \mathrm{mN}(\mathrm{Si})$ & $\mathrm{x}$ & $\begin{array}{c}0 \\
\text { Temperature }\end{array}$ & [31] \\
\hline & Pillar & PDMS & $2.6 \pm 0.2 \mathrm{~N} / \mathrm{cm}^{2}$ (Glass) & $\mathrm{x}$ & $\begin{array}{c}0 \\
\text { Pneumatic }\end{array}$ & [18] \\
\hline & Geko & PDMS & $1.44 \mathrm{~N} / \mathrm{cm}^{2}$ (Glass) & $\mathrm{x}$ & $\begin{array}{c}0 \\
\text { Pneumatic }\end{array}$ & [20] \\
\hline \multirow{6}{*}{$\begin{array}{c}\text { 3d } \\
\text { Suction } \\
\text { cup }\end{array}$} & Octopus suction cup & PDMS & $2.5 \mathrm{~N} / \mathrm{cm}^{2}$ (Si wafer) & $4 \mathrm{~N} / \mathrm{cm}^{2}$ (Si wafer) & $\mathrm{x}$ & [39] \\
\hline & Octopus suction cup & PDMS & $3 \mathrm{~N} / \mathrm{cm}^{2}$ (Si wafer) & $11 \mathrm{~N} / \mathrm{cm}^{2}$ (Si wafer) & $x$ & {$[41]$} \\
\hline & Octopus suction cup & PDMS & $3 \mathrm{~N} / \mathrm{cm}^{2}$ (Pig skin) & $1.3 \mathrm{~N} / \mathrm{cm}^{2}$ (Pig skin) & $x$ & [42] \\
\hline & Frog and Octopus suction cup & PDMS & $6.6 \mathrm{~N} / \mathrm{cm}^{2}$ (Si wafer) & $5.3 \mathrm{~N} / \mathrm{cm}^{2}$ (Pig skin) & $x$ & [11] \\
\hline & Octopus suction cup & Hydrogel (pNIPAM) & $9.4 \mathrm{~N} / \mathrm{cm}^{2}$ (Si wafer) & $x$ & $\begin{array}{c}0 \\
\text { Temperature }\end{array}$ & [17] \\
\hline & Octopus suction cup & PDMS & $5 \mathrm{~N} / \mathrm{cm}^{2}$ (Si wafer) & $4.9 \mathrm{~N} / \mathrm{cm}^{2}$ (Si wafer) & $\begin{array}{c}0 \\
\text { Electrothermal }\end{array}$ & $\begin{array}{c}\text { Current } \\
\text { work }\end{array}$ \\
\hline
\end{tabular}




\section{Supporting Information Figures}

a

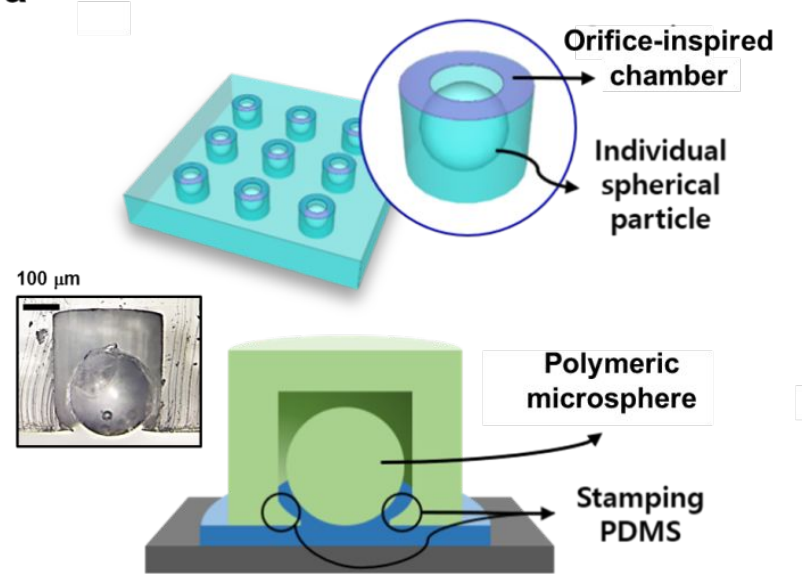

b

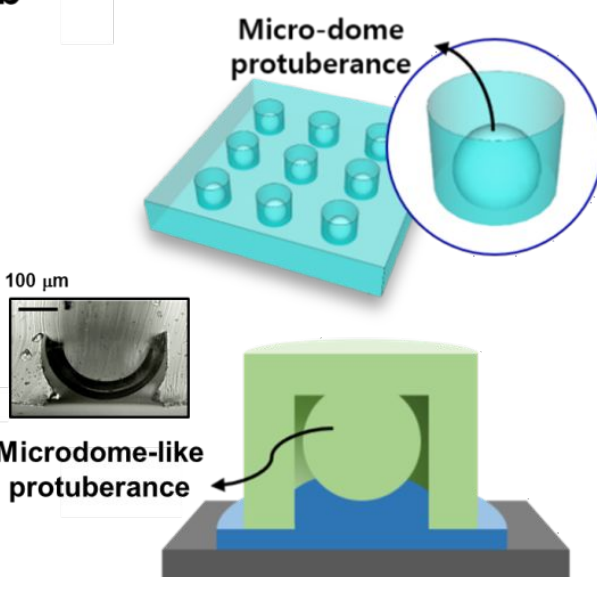

Figure S-1. The illustrations and optical microscopic image of (a) OMS adhesive structure and

(b) dome-like adhesive structure (ODA). 


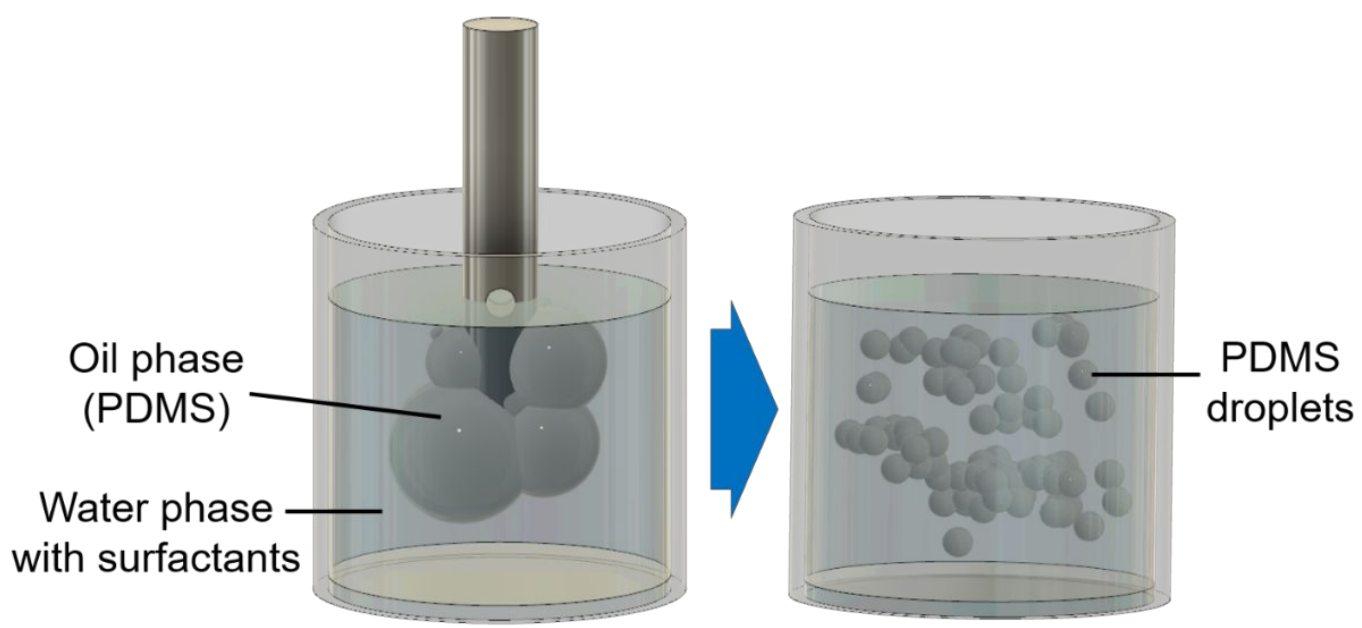

Figure S-2. Schematic fabrication of the microspheres by emulsion polymerization. 

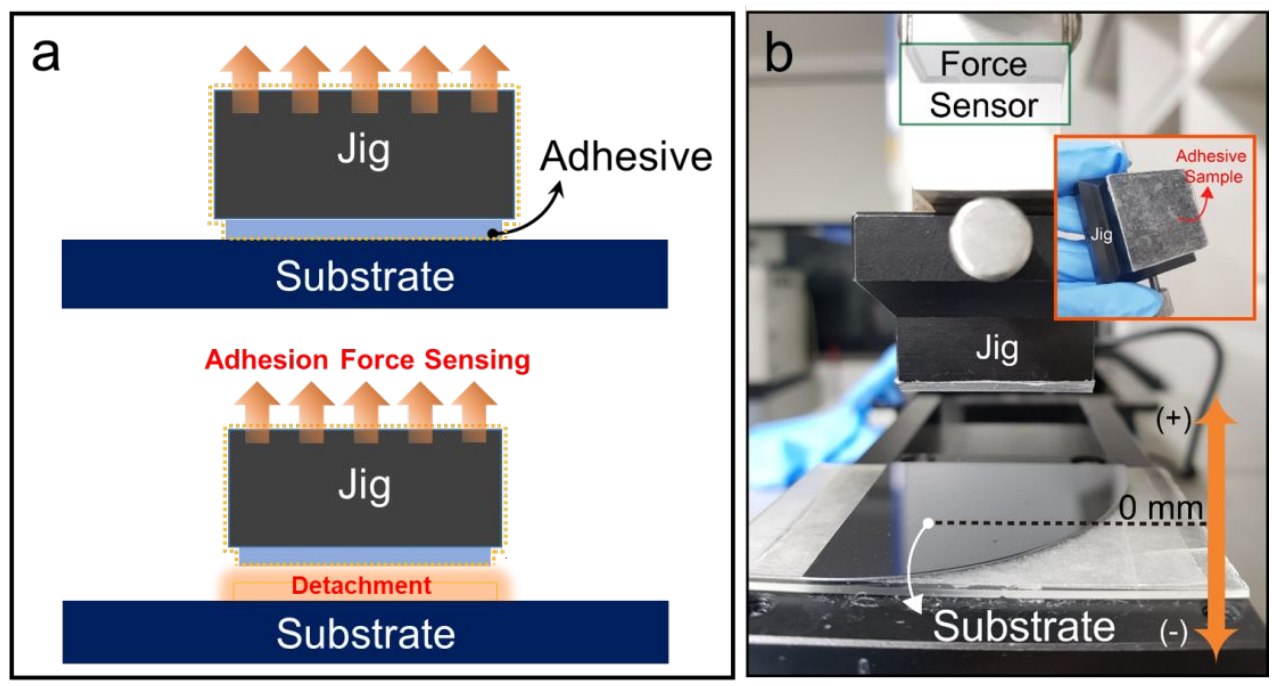

Figure S-3. (a) Schematic illustration and (b) the photograph images of pull-off adhesion measurements using custom-built equipment. The inset photograph of (b) shows the adhesive sample attached onto the tester zig and silicon wafer affixed to the bottom. 


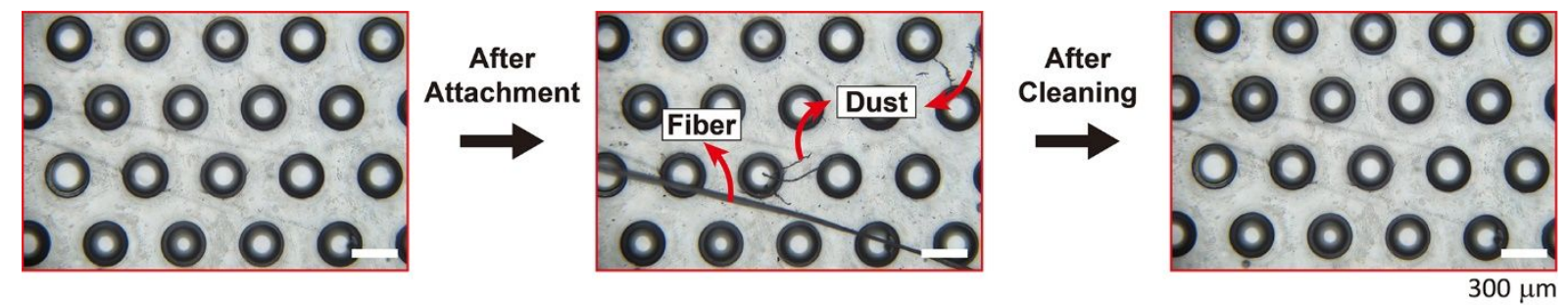

Figure S-4. OM images of OMS patche after attachment and detachment. After cleaning surface of the patch by rinsing with water and blowing air, impurities (dust particles and fibers) were easily removed. 
a

(i)

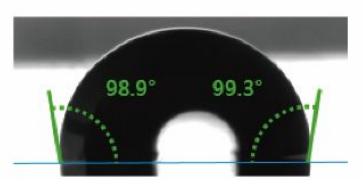

Non-treated PDMS

(ii)

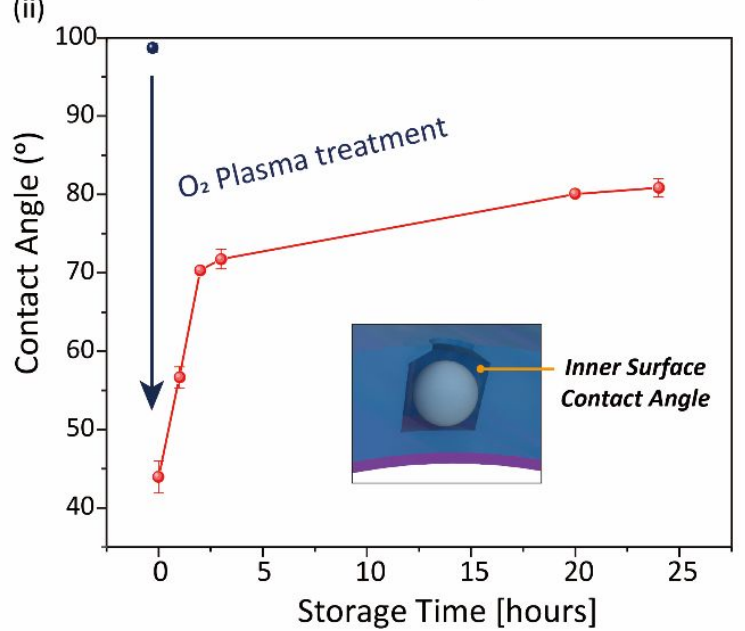

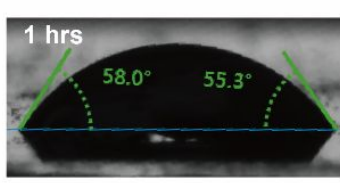

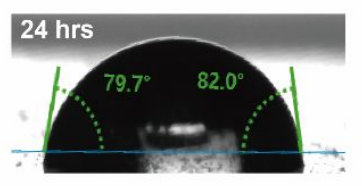

Aging Time

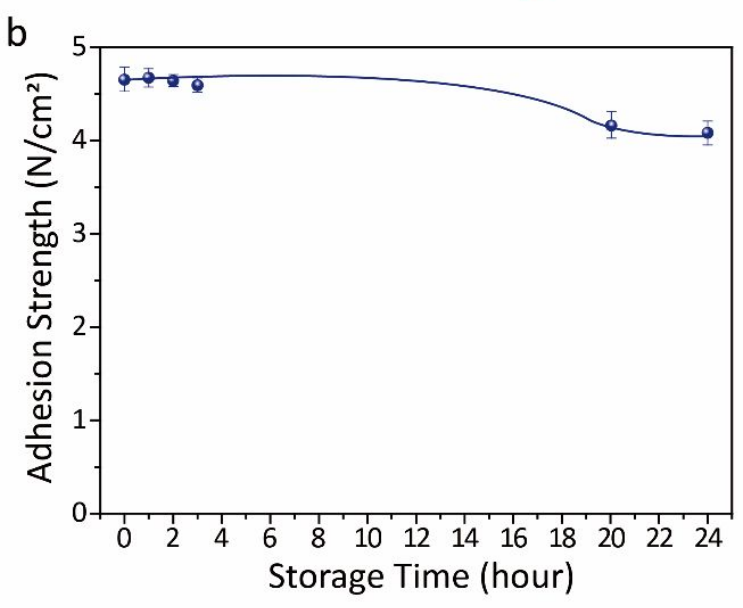

Figure S-5. (a) Photographic images (i) and a plot (ii) showing time-dependent difference of contact angle of an oxygen plasma-treated PDMS. (b) Time-dependent adhesion strengths of the adhesive device after $\mathrm{O}_{2}$ plasma-treatment. Here the adhesion forces were measured against a silicon wafer in underwater conditions. 


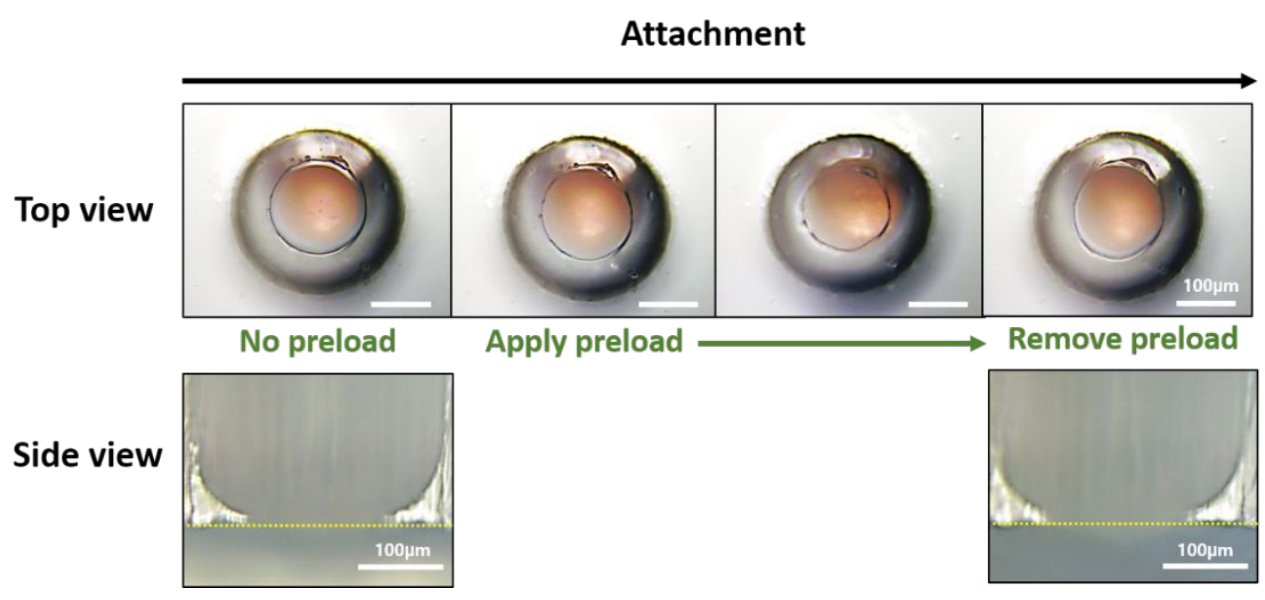

Figure S-6. Top view and cross-sectional OM images of the OMS patch surface before and after the application of the preload. Conformal contacts of the orifice structure against wafer substrate were observed during the application and removal of the preload. 
a
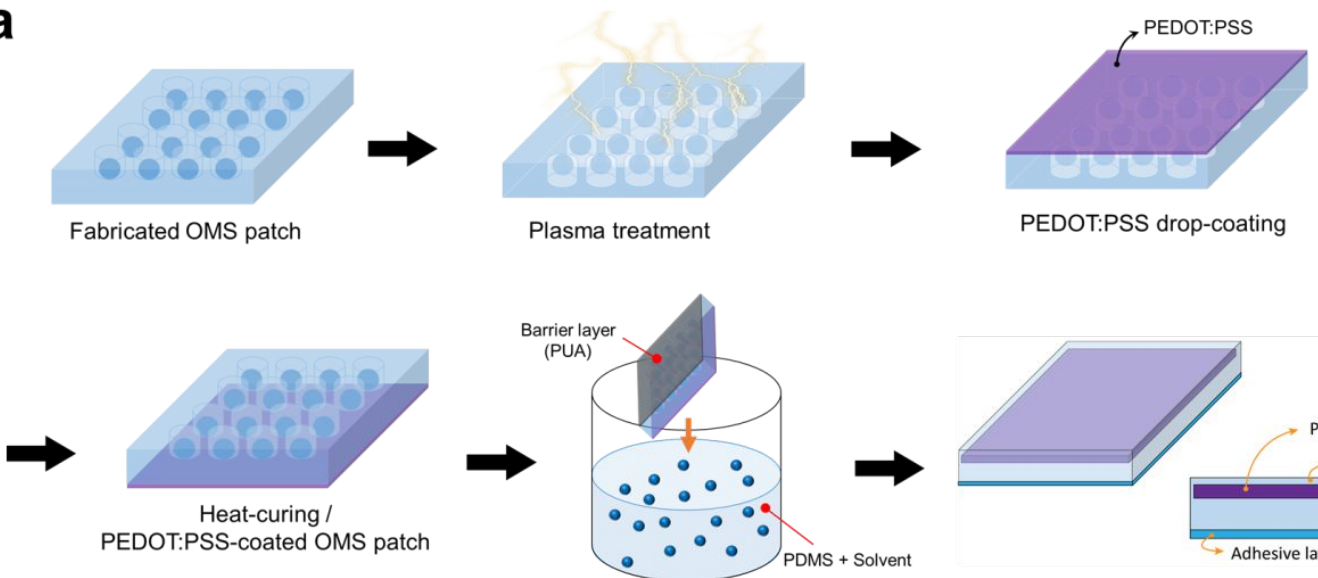

Dip coating for sealing

b
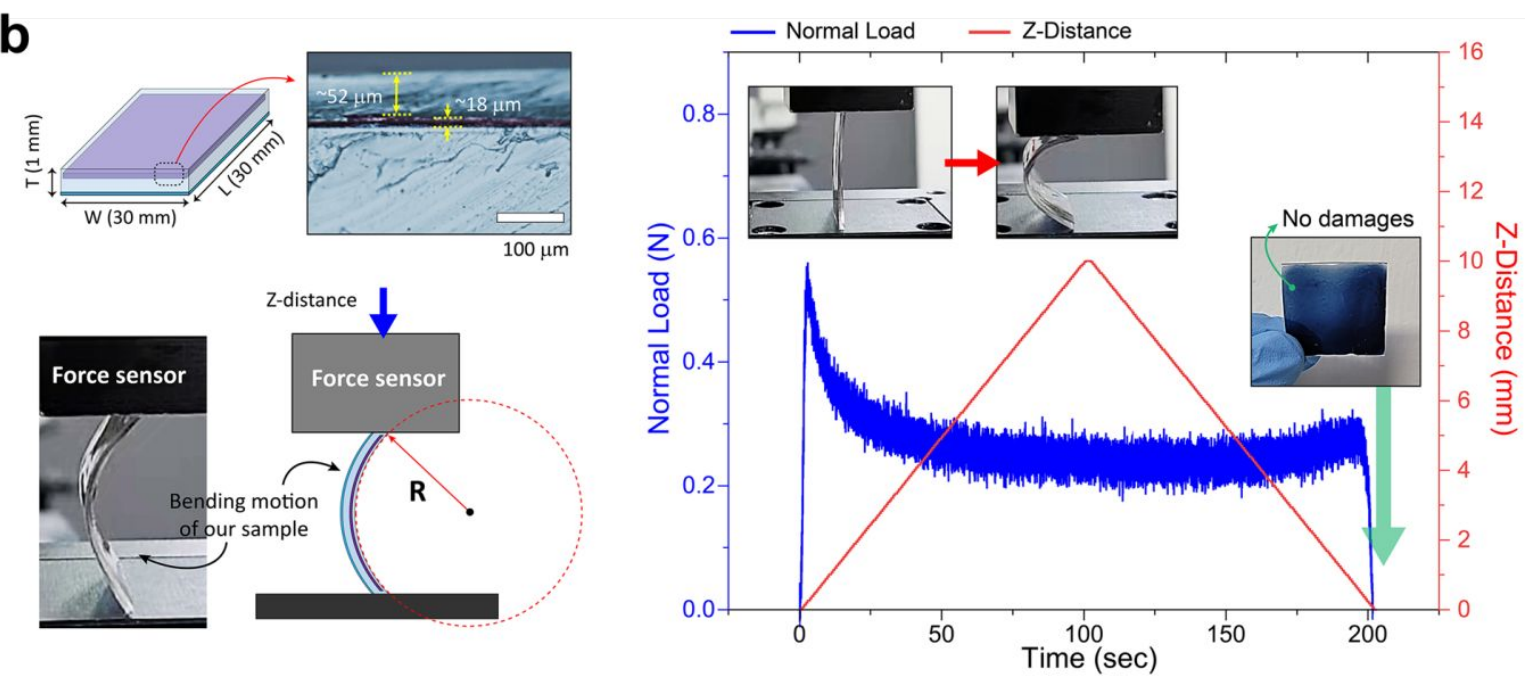

Figure S-7. (a) Schematic illustration of fabrication process of a OMS adhesive embedded with a PEDOT:PSS layer. (b) Mechanical stress tolerance of the polymeric bilayer actuator (OMS adhesive) depending on bending motion. As applying bending stress, the sample was bent with a curvature of $\sim 0.104 \mathrm{~mm}^{-1}$. Hardly any damages (e.g. crack, delamination, or other breakages) were observed during bending motions. 
a

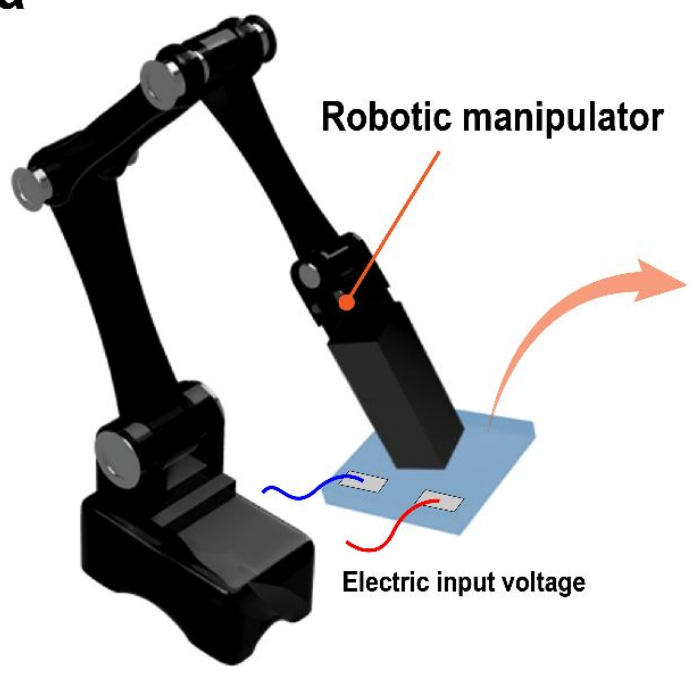

b

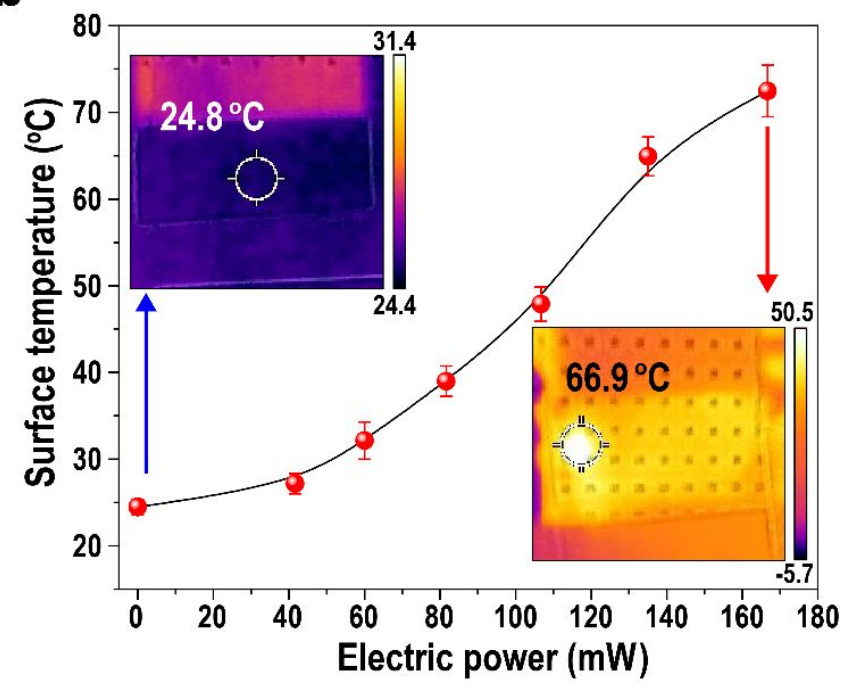

Figure S-8. (a) Schematic illustration of the polymeric bilayer actuator integrated to a robotic manipulator. (b) Temperature measurements of the actuator with respect to input power. 


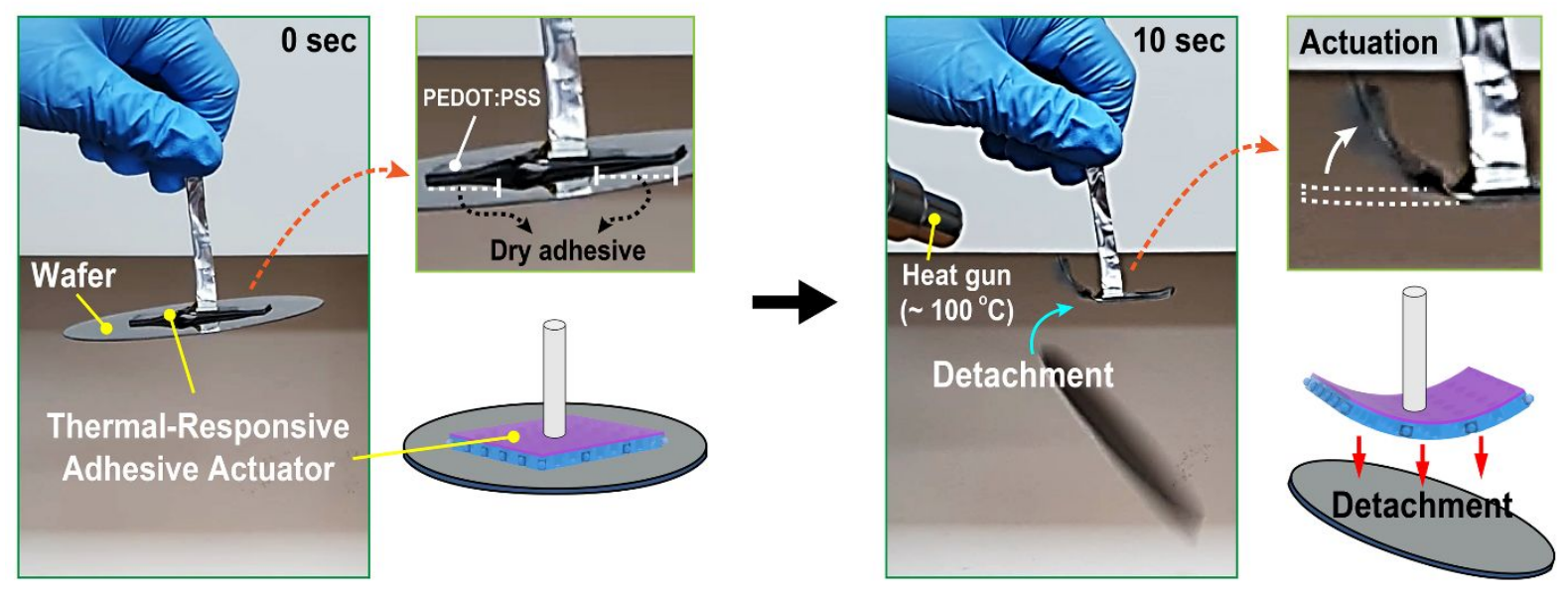

Figure S-9. Representative photographs which indicate attachment (left) and detachment (right) of the actuator before/after heat is applied. 
a

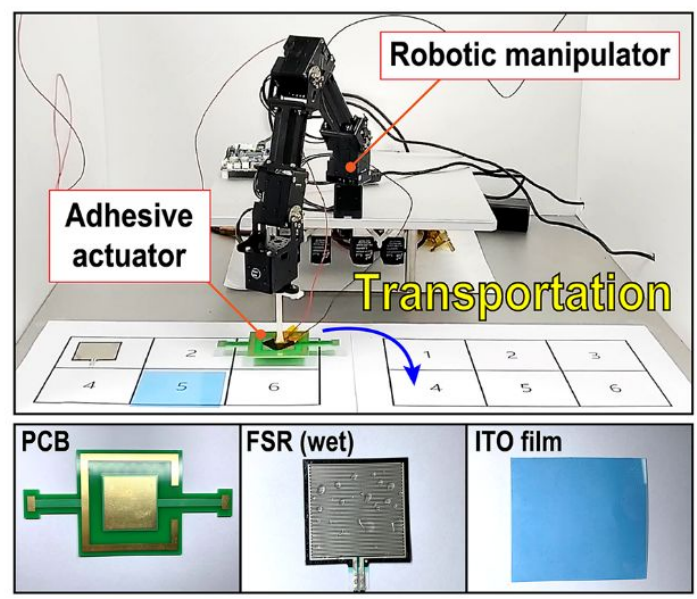

\begin{tabular}{cc}
\hline Substrate & $\begin{array}{c}\text { RMS roughness } \\
(\mathrm{nm})\end{array}$ \\
\hline Si wafer & 0.527 \\
PCB electrode & 60.165 \\
FSR electrode & 10.965 \\
FSR substrate & 13.159 \\
ITO & 13.165 \\
\hline
\end{tabular}

b
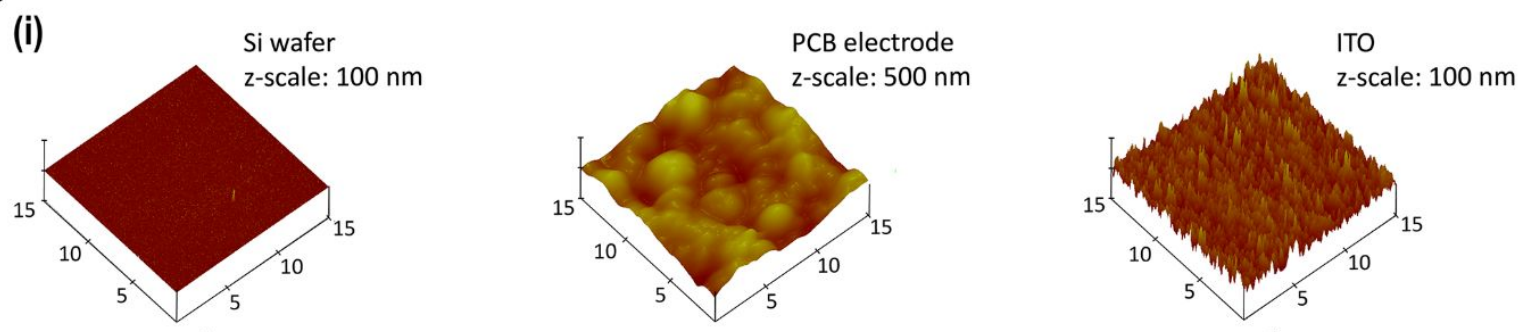

(ii-1)

(ii-2)
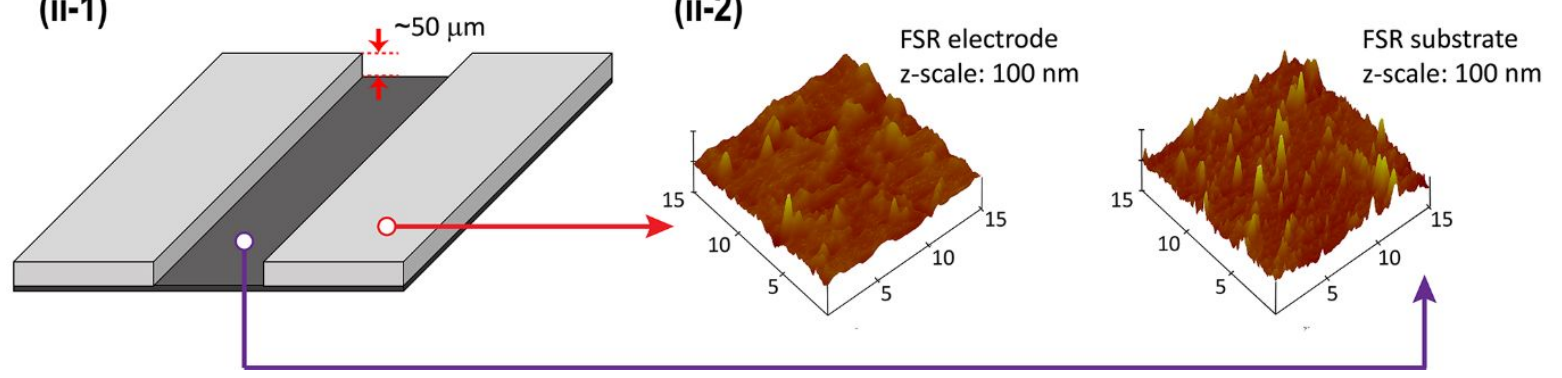

Figure S-10. Application of OMS adhesive actuator for transporting various substrates. (a) Photographic images of actuator adhesive connected to the robotic manipulator for rearrangement of various delicate objects, including FCB electrode, wet FSR, and ITO film. Right table shows the roughness data of the applied substrates. (b) AFM (Atomic force microscopes) images of Si wafer, PCB electrode, ITO film, and FSR. Here, FSR contains electrode part and substrate part. 


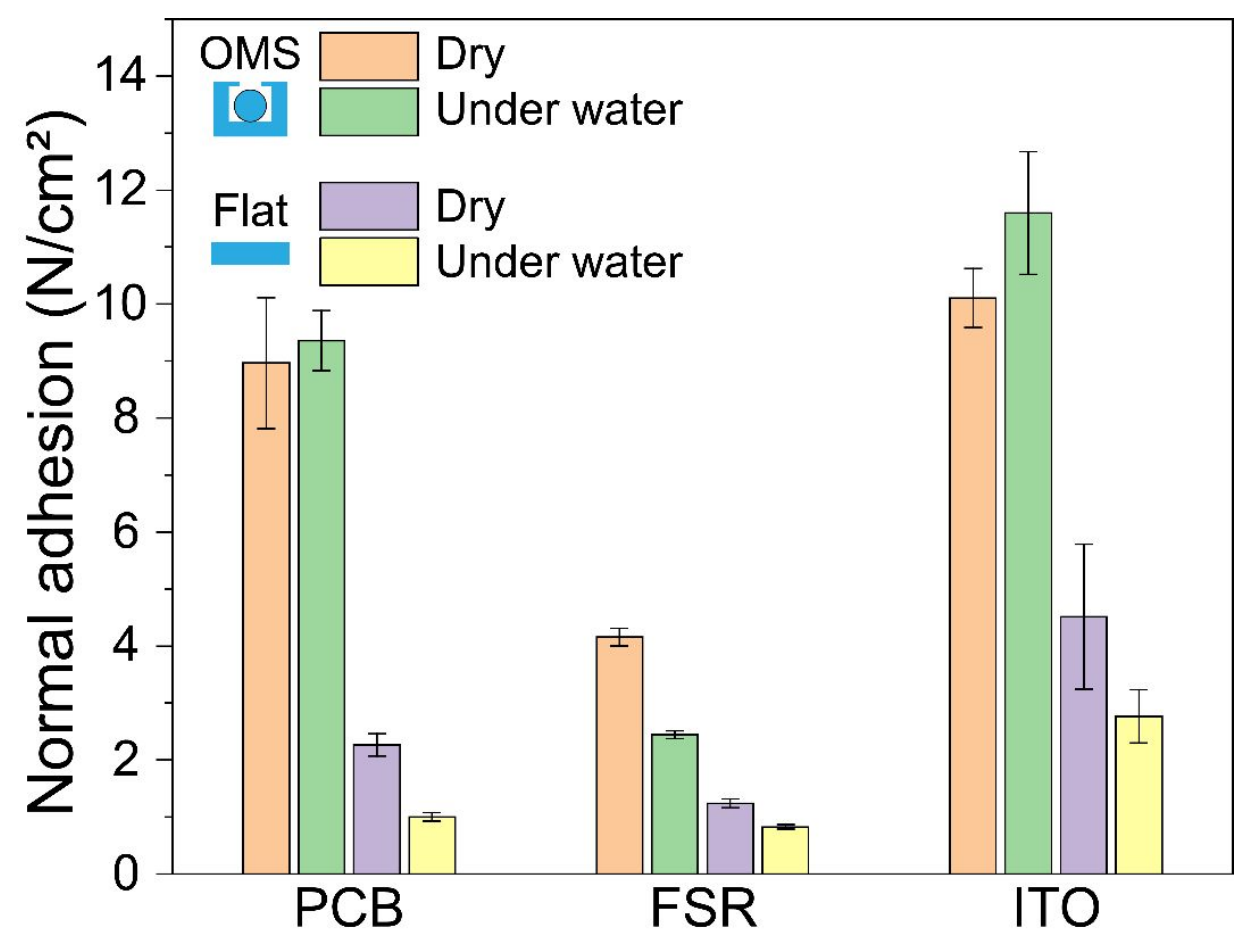

Figure S-11. Normal adhesion strengths of OMS patch and flat patch against various substrates of PCB, FSR, and ITO in both dry and underwater conditions. 


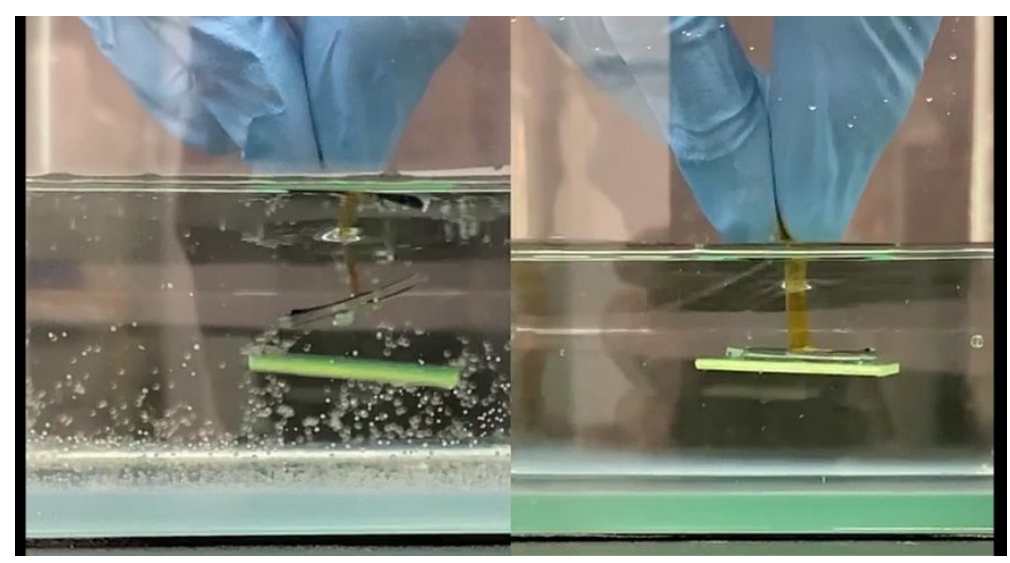

Supporting Information Video 1. Demonstration of self-detachment of adhesive patch in hot water $\left(\sim 80{ }^{\circ} \mathrm{C}\right)$, compared with the device in cool water $\left(\sim 15{ }^{\circ} \mathrm{C}\right)$. 


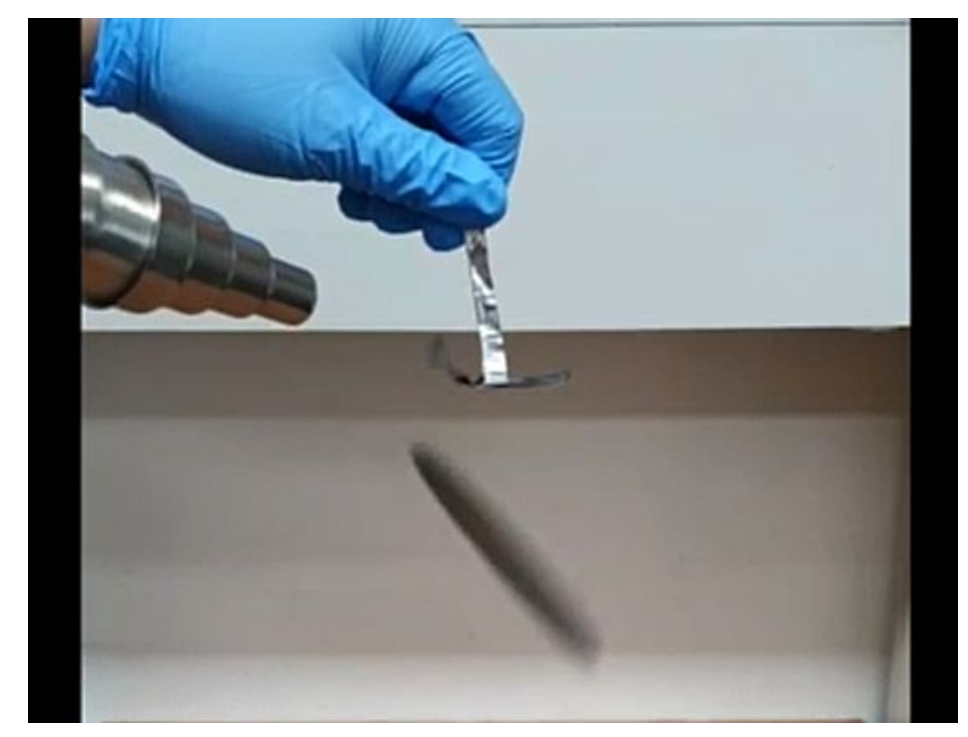

Supporting Information Video 2. Self-detachment of the OMS adhesive patch with a thermally responsive actuator to wafer substrate during the application of heat. 


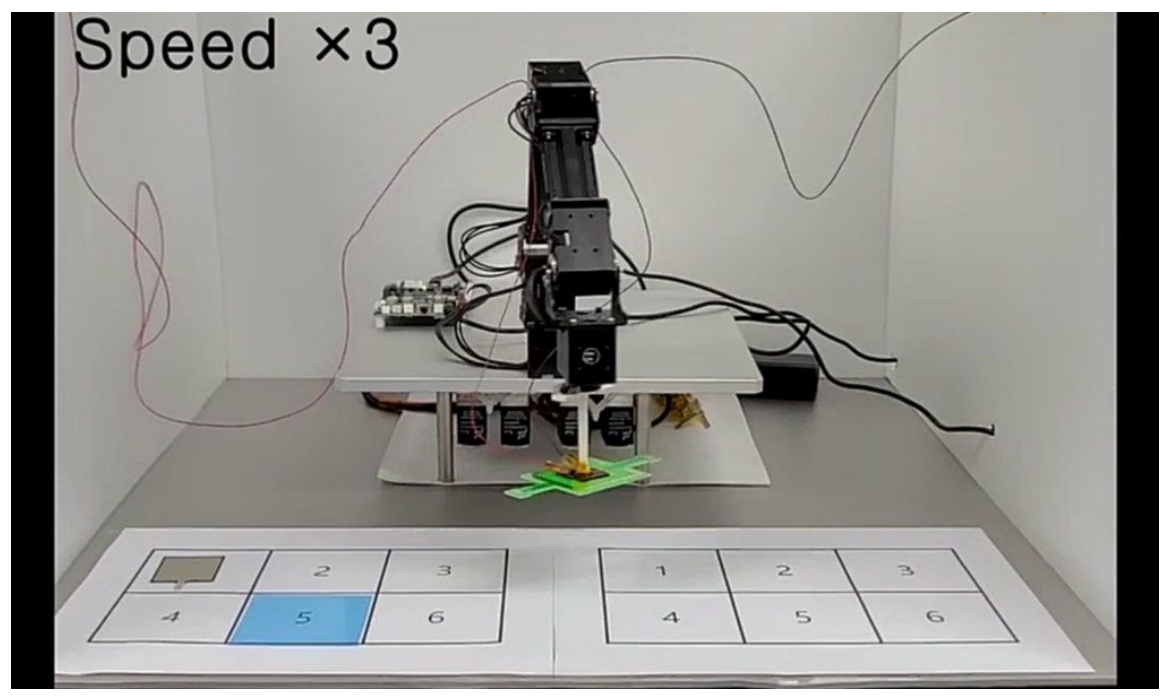

Supporting Information Video 3. OMS patch integrated to a robotic manipulator for grasp, transport, and detachment of various delicate objects. 


\section{References}

(1) Crisp, A.; de Juan, E.; Tiedeman, J. Effect of Silicone Oil Viscosity on Emulsification. Archives of ophthalmology 1987, 105 (4), 546-550.

(2) Hüsler, A.; Haas, S.; Parry, L.; Romero, M.; Nisisako, T.; Williams, P.; Wildman, R. D.; Alexander, M. R. Effect of Surfactant on Pseudomonas Aeruginosa Colonization of Polymer Microparticles and Flat Films. RSC advances 2018, 8 (28), 15352-15357. 